\title{
Octavio Paz e o labirinto da América Latina
}

\author{
Júlio Pimentel Pinto* \\ juliop@uol.com.br
}

\begin{abstract}
RESUMO: Ao retomar a trajetória biográfica de Octávio Paz, assim como ao aludir ao contexto da escrita, da publicação e das reedições de O labirinto da solidão, pretendese discutir a importância da questão identitária na América Latina, de forma geral, e no México, de forma particular. Acompanhando o esforço de representação do mexicano na obra citada, busca-se reavaliar as críticas endereçadas ao texto de Paz, considerando a atualidade do seu escrito pela estreita vinculação a um desejo de identidade, ao mesmo tempo, constante e em transformação.
\end{abstract}

Palavras-Chave: Identidade, Octávio Paz, México.

\section{IDENTIDADE, POR QUÊ?}

O filósofo mexicano Leopoldo Zea (1982) afirmou que o tema da identidade é o que permite à América Latina viajar constantemente "em busca de si mesma". Por sua vez, a crítica Irlemar Chiampi (1980) enfatizou que a busca dessa identidade foi o "motor do pensamento americanista". Ambos estão, evidentemente, corretos. E é, ainda, pertinente atestar que boa parte da historiografia e da crítica cultural latino-americana (ou sobre a América Latina) se engalfinha, ainda hoje, nas discussões acerca do que é o latino-americano e, tantas vezes, nos exercícios simultâneos, aparentemente coerentes, mas algo paradoxais, de denegar matrizes de formação e afirmar a originalidade plena do processo histórico de formação cultural - isso porque as discussões étnicas saíram do centro da pauta americanista. Finalmente, é também correto afirmar que o livro de ensaios mais conhecido de Octavio Paz - O labirinto da solidão, publicado originalmente em 1950 - dispõe-se a investigar os caminhos peculiares da identidade mexicana (1984).

Professor do Departamento de História da USP. 
Ao destacar a preocupação identitária no Brasil - mas com argumentos que são igualmente adequados ao contexto latino-americano -, o historiador da arte e professor do departamento de história da Unicamp Luiz Marques (2001, p. 13), ex-curador do acervo do Museu de Arte de São Paulo (MASP), observou que

vale lembrar que a noção mesma de identidade, pertencente ao domínio da psicologia, nunca deixou de promover aberrações quando transplantada para o terreno da cultura. Deste transplante redundam, com efeito, impasses ou contradições facilmente identificáveis.

E, em seguida, Marques (2001, p. 13) anunciou as contradições dos esforços identitários, aumentando um pouco nossa preocupação acerca de como lidar com o tema: "A primeira delas é que a identidade não pode ser uma meta, uma construção, pois ou é um a priori absolutamente objetivo, involuntário e inconsciente de si, ou não é, e não será jamais, identidade".

A idéia, não por acaso, já estava em dois dos maiores escritores que a América Latina teve: Machado de Assis, no incrível Instinto de nacionalidade, de 1873, e Jorge Luis Borges, principalmente (mas não só) em seus escritos posteriores aos anos 1930. Ou seja, a identidade só pode existir em duas condições: ou ela é natural (e, nesse sentido, não comporta quaisquer discussões ou problematizações; resta apenas assumi-la e aceitá-la) ou é uma construção (portanto, não oferece nenhuma possibilidade de espelho absoluto e definido; não "identifica", pois não torna ninguém idêntico ao outro ou ao modelo). E, em qualquer dos casos, deve ser considerada - o alerta também é antigo - com o cuidado de não a supor tão ampla, que a tudo abarque, nem tão limitada, que só a encontremos no espelho.

Não se trata de questão retórica na tradição cultural latino-americana. Primeiro, pela já destacada força da questão identitária no pensamento americanista. Segundo e, sobretudo, pelos inúmeros usos, inclusive políticos, da defesa da identidade - pela direita ou pela esquerda, pelos governos ou por seus adversários, pelas políticas culturais de variadas ordens, pelos inúmeros projetos de afirmação cultural (os exemplos são incontáveis, com consistências, estratégias de aplicação e efeitos dos mais diversos: do peronismo à política cultural federal de hoje; do varguismo aos CPCs da UNE, da mistificação em torno da "autonomia paraguaia" no período Francia-López ao "bolivarianismo" chavista). Evidentemente, tal uso não é ilegal, ilícito ou equívoco, entretanto, precisa ser tomado pelo que é: um manejo ideológico (no sentido estrito), que inúmeras vezes dispusemos-se 
a "naturalizar" a identidade e, a partir dos resultados da identificação constituída, formular as bases de sua afirmação ou da defesa de interesses (políticos, culturais, sociais etc.) específicos, mascarados como manifestação de algo coletivo. Tomar as construções identitárias pelo que são - com sua, repitamos, forte carga ideológica - é inclusive a única maneira de evitar que sucumbamos ao peso de uma proposta uniformizadora e autoritária no âmbito da cultura. O princípio dessa crítica foi destacado por Marques (2001, p. 13) no texto que seguimos até agora:

Nenhuma cultura pode se dar por programa tornar-se ela mesma, tornar-se mais autêntica, pela simples razão que a autenticidade não é por definição um constructo. A identidade é um inevitável já dado, é um ponto de partida involuntário, não um ponto de chegada.

E isso porque, já de saída, a busca de uma identidade deriva, arremata Marques (2001, p. 15), de uma contradição:

Chegamos, assim sendo, a uma terceira aporia evidente: a identidade nacional como programa é uma denegação, pois sua reivindicação é ipso facto confissão de sua ausência. E quando esta reivindicação formula-se como negação do modelo europeu, as coisas pioram ainda mais. Pois a ninguém escapa que se afirmar como negação implica frisar a supremacia do modelo negado, de existência logicamente prévia e positiva. Assim, quanto mais se tentou e se tenta afirmar a identidade nacional, mais fortemente se reafirmou e se reafirmará sua inexistência.

Será que Octavio Paz, ao tratar do tema da mexicanidade, desconhecia os dilemas e percalços dos esforços identificadores - e a historicidade da identidade como preocupação e móvel do pensamento americanista? A pergunta, evidentemente, é apenas retórica; Paz sabia, e bem, das limitações de toda indagação identitária - e dos ocasionais resultados a que ela chegasse. Tanto é que elegeu uma metáfora que assume o sentido da aporia: o labirinto. E foi por meio desse recurso de estilo que Paz pensou a peculiaridade da formação mexicana e, por extensão, da América Latina, e o problema de sua identificação.

QUANDO E POR QUE PAZ ESCREVEU O LABIRINTO DA SOLIDÃo?

Em primeiro lugar, datemos o livro de oito ensaios do qual partimos. O labirinto da solidão foi publicado em 1950, pelos Cuadernos Americanos. 
Em 1959, a Fondo de Cultura Económica lançou a segunda edição, revista e aumentada, em que Paz aproveitou, provavelmente, as mudanças feitas para a tradução francesa (também de 1959) e alterou, sobretudo, sua interpretação da Revolução Mexicana. Além disso, incluiu um novo ensaio - Nossos dias, que passou a ser o oitavo, transformando o antigo ensaio número oito, Dialética da solidão, num apêndice. A partir de 1970, as edições passaram a contar com o Postdata - na origem, uma conferência proferida na Universidade doTexas, em Austin, em dezembro de 1969. Em 1975, Paz concedeu uma longa entrevista a Claude Fell, intitulada Vuelta a El laberinto de la soledad - a entrevista foi publicada em novembro daquele ano no número 50 da revista mexicana Plural e, depois, compilada no volume de ensaios $E l$ ogro filantrópico, de 1979. Passou a incorporar, também, as edições de $O$ labirinto da solidão.

Contudo, nos fixemos à escritura e à primeira publicação do livro, no imediato pós-Segunda Guerra Mundial. O impacto do conflito na redação da obra foi declarado pelo próprio Paz (1984, p. 154):

Depois da Segunda Guerra Mundial, percebemos que esta criação de nós mesmos que a realidade exige não é diferente da que uma realidade semelhante reclama dos outros. Vivemos, como o resto do planeta, uma conjuntura decisiva e mortal, órfãos do passado e com um futuro a ser inventado. A história universal já é tarefa comum. E o nosso labirinto, o de todos os homens.

Para Silviano Santiago, era o reconhecimento de que "a força nacionalista latino-americana" foi "neutralizada" pela "sua inscrição no Ocidente e no planeta”, provocada pela Segunda Guerra. O predomínio norte-americano na região, agora incontestável, e sua decorrente "exportação de influência, vigilância, controle e poder” (SANTIAGO, 2006, p. 17-18) impediam a crença num ocasional isolamento latino-americano e forçavam o reconhecimento - repito a palavra, mas por falta de sinonímia tão forte - de que a política e a cultura latino-americana agora se jogavam no plano universal - o que podia reforçar o sentido da prospecção identitária e provocar o surgimento de novas formas de afirmação (ou desejo) de autonomia, mas, sobretudo, implicava no redimensionamento da questão em função do "novo lugar no mundo". Santiago reforça, ainda, o que lhe parece um compromisso político que envolveu a obra - não por acaso, publicada em tempos de franca aposta no desenvolvimento: uma crença na "possibilidade ufanista e, paradoxalmente, universal de desenvolvimento econômico dos países atrasados" (SANTIAGO, 2006, p. 19); o termo "atrasados", observa 
ainda o autor, sempre aparece entre aspas, o que indica o otimismo "consciente ou inconsciente" de superação da condição secundária.

Mas a discussão sobre o contato com o mundo, para Paz - como para muitos hispano-americanos -, não se iniciou com a Guerra. Foi um pouco antes, e no cenário rebelde da Guerra Civil espanhola, em 1936, ou mais cedo, e ainda na infância. É sabido que o pai de Paz, Octavio Paz Solórzano, zapatista, foi exilado do México nos anos que se seguiram à Revolução de 1910-1917. Paz, nascido em 1914, tinha seis anos, seguiu o pai e passou a viver na imensa colônia de desterrados políticos hispano-americanos de Los Angeles. Em suas palavras:

Tinha seis anos, e não falava uma só palavra de inglês. Lembro vagamente do primeiro dia de aula: a escola com a bandeira dos Estados Unidos, a classe sem decoração, as carteiras, os bancos duros e meu susto diante da ruidosa curiosidade de meus colegas e o sorriso amável da jovem professora, que procurava aplacá-los. Era uma escola angloamericana e apenas dois dos alunos eram de origem mexicana, ainda que nascidos em Los Angeles. Aterrorizado por minha incapacidade de compreender o que me diziam, me refugiei no silêncio. Ao fim de uma eternidade chegou a hora do recreio e do lanche. Ao sentar-me na mesa, descobri com pânico que me faltava uma colher; preferi não dizer nada e ficar sem comer. Uma das professoras, ao ver meu prato intacto, me perguntou, com sinais, a razão. Sussurrei 'cuchara', apontando a do colega mais próximo. Alguém repetiu em voz alta: ‘¡cuchara!'. Gargalhadas e algazarra. Começaram as deformações verbais e o coro das gozações. O bedel impôs silêncio, mas na saída, no arenoso pátio esportivo, a gritaria me rodeou. Alguns se aproximavam e me jogavam na cara, com uma cusparada, a palavra infame: '¡cuchara!' Um deles me deu um empurrão, eu tentei revidar e, imediatamente, me vi no meio de um círculo: diante de mim, com os punhos fechados e em atitude de boxeador, meu agressor me provocava, gritando-me: '¡cuchara!' Trocamos golpes até que um bedel nos separou. Ao sair, nos repreenderam. Não entendi uma palavra da bronca e voltei para casa com a camisa rasgada, três arranhões e um olho semi-fechado. Não voltei à escola por quinze dias; depois, pouco a pouco, tudo se normalizou: eles esqueceram a palavra cuchara e eu aprendi a dizer spoon. (PAZ, 1993, p. 15-18)

A história, bastante comum nos meios infantis, teve - diz ele - caráter exemplar. Era um aprendizado da diferença e, claro, da intolerância diante da diferença. E tudo piorou, insiste Paz, na volta para o México, após dois anos de exílio. Os colegas da nova escola mexicana, uma escola francesa,

Júlio Pimentel. Octavio Paz e o labirinto da América Latina 
não demoraram para decidir que eu era um estrangeiro. [...] Saber que eu era recém-chegado dos Estados Unidos e minha aparência - cabelos castanhos, pele e olhos claros - poderia explicar sua atitude; não totalmente: minha família era conhecida em Mixcoac [...] Voltaram os risos e as gozações [...]. (PAZ, 1993, p. 15-18)

Seguindo os passos da criança que Paz foi, o resultado é que

A experiência de Los Angeles e a do México me provocaram pesadelos durante muitos anos. Às vezes pensava que era o culpado - com freqüência somos cúmplices de nossos perseguidores -e me dizia: sim, eu não sou daqui nem de lá. Então, de onde sou? Eu me sentia mexicano o sobrenome Paz aparece no país desde o século XVI, dia seguinte da Conquista - mas eles não me deixavam sê-lo. (PAZ, 1993, p. 15-18)

É tripla, além de exemplar, a condenação para aquele que não é igual. O desterro, lembra Paz, é um tema recorrente desde a figuração dos filhos de Adão; portanto, seu sentido é universal. No entanto, as outras duas condenações são históricas: o mexicano nos Estados Unidos e o estrangeiro no México. Sob as três figuras, universais ou históricas, vige o signo da suspeita, daquele que não é digno da confiança, porque indecifrável: vive e funciona segundo outro código. E, destaca Paz, poucas características mexicanas são tão destacadas como a suspeita e a desconfiança. Daí a disposição de entender as bases históricas dessa atitude perante o outro.

$\mathrm{Na}$ origem de O labirinto da solidão, portanto, havia questões de toda ordem: do panorama histórico trágico da Guerra Civil espanhola e da Segunda Guerra Mundial à experiência individual de uma infância que, até por não ser incomum em seus problemas, ativou a disposição investigadora do adulto. E, finalmente, a percepção de que havia um traço específico do mexicano na agudeza da reação ao outro, um conflito interno ao México que precisava ser visto e analisado. Por isso,conclui, escreveu o livro:

Por tudo isso não é estranho que, desde minha adolescência, me intrigasse a desconfiança mexicana. Parecia-me a conseqüência de um conflito interior. Ao refletir sobre sua natureza, constatei que, mais do que um enigma psicológico, era o resultado de um trauma histórico enterrado nas profundidades do passado. A desconfiança, em vigília perpétua, cuida para que ninguém descubra o cadáver e o desenterre. Essa é sua função psicológica e política. Pois bem, se a raiz do conflito é histórica, só a história pode esclarecer o enigma. [...] Sem me dar conta do que 
fazia, movido por uma intuição e picado pela memória de minhas três experiências, quis romper o véu e ver. (PAZ, 1993, p. 21-22)

Os temas e as preocupações do livro também foram ensaiados muitos - pelo menos 12 - anos antes. Na década de 1940, um terço dos artigos que escreveu para o diário Novedades, da Cidade do México, abordavam a questão da identidade mexicana, compondo uma espécie de "pré-história ou premonição de O labirinto da solidão" (SANTIAGO, 1997, p. 139).

O livro foi escrito em Paris, entre 1948 e 1949, onde Paz vivia desde o final de 1945, ocupando um posto secundário na Embaixada mexicana. Ele reconhece que a distância do México e a pouca ocupação no verão de 1949 o ajudaram a redigir a primeira versão da obra nas tardes das sextas, nos sábados e nos domingos e nas demais noites da semana. Escreveu rapidamente: "disputava uma corrida comigo mesmo" e aguardava, ansioso, o desfecho. A ânsia de acabar logo traduzia, diz, a expectativa de que na última página chegasse à revelação. "Quem eu iria encontrar no final? Conhecia a pergunta, não a resposta” (PAZ, 1993, p. 28-29).

\section{RepresentaÇÃO: DESLOCAMENTO \& DUPLICAÇÃO}

Evidentemente que não havia nenhuma resposta à espera. E o que Paz considerou uma "vingança contra o México e contra si mesmo", contaminada por uma relação ambígua de amor e de ódio, acabou por se converter num livro de história. Sobre a história do México, sobre o próprio funcionamento da história e de seus mecanismos de representação e um livro de história que não agradou especialmente aos mexicanos. Apesar de uma resenha parcialmente elogiosa recebida do importante intelectual mexicano José Vasconcelos, a reação foi, a princípio, silenciosa - um silêncio eloqüente. Apenas seis resenhas da primeira edição apareceram e praticamente se limitavam à descrição do livro (SANTI, 1997, p. 154). Três anos depois, as discordâncias apareceram. Em 1953, Juan Hernández Luna (apud SANTi; 1997, p. 155-156) publicou uma resenha violentíssima, em que acusava Paz de escrever contra o México e de desconhecer os "verdadeiros mexicanos" e privilegiar os que

não gostam de nosso país, que renegam suas tradições e que se exilam voluntariamente nos Estados Unidos ou na Europa', 'grupos de solitários, de derrotados', que 'jamais podem ser tomados como protótipo da mexicanidade’e que Hernández Luna associa, finalmente, com 'o mexicano conservador, o mexicano católico que não dá valor' à 'tradição re- 
volucionária', cujos análogos contemporâneos seriam 'o nazista alemão e o fascista italiano, a quem a segunda guerra mundial deixou sós e órfãos.

Na prática, Hernández Luna, por trás do aparente existencialismo essencialista, apenas pretendia, na boa tradição corporativa da academia, defender seu colega de departamento Samuel Ramos, que ele julgou criticado pelo livro de Paz - e era criticado de fato, sem que isso invalidasse a importância que os estudos de Ramos tiveram para Paz. Incrível é que essas críticas - insustentáveis à luz de uma boa leitura da obra - continuam sendo repetidas, ainda hoje, pelos desafetos de Paz e por aqueles que o consideram inimigo ideológico, principalmente nas academias latino-americanas. O enfurecido nacionalismo da crítica, de alguma forma, comprovou que a tese de Paz, afinal, estava correta - como ele mesmo, na expectativa de reações duras ao livro, advertira, em carta escrita a Alfonso Reyes, em 23 de novembro de 1949 (antes, portanto, da publicação do livro):

Não faltará quem use os dentes afiados de sempre e que o acuse de dar as costas ao México. [...] lhe confesso que o tema do México - imposto por decreto de algum imbecil convertido em oráculo da 'circunstância' e do 'compromisso' - começa a me pesar. E se eu mesmo acabei por escrever um livro foi para me livrar dessa enfermidade que seria grotesca se não fosse perigosa e escondesse um desejo de nivelar tudo. Um país bêbado de si mesmo - em uma guerra ou em uma revolução - pode ser um país são, recheado de essência ou em busca dela. Mas essa obsessão na paz revela um nacionalismo torto, que desemboca em agressão, quando se é forte, e em narcisismo e masoquismo, quando se é miserável, como ocorre conosco. [...] Ou para dizer mais claramente: temo que, para alguns, ser mexicano consiste em algo tão especial que nos nega a possibilidade de sermos homens, a seco. E lembro que ser francês, espanhol ou chinês são apenas maneiras de ser algo menos que o francês, o espanhol ou o chinês. (PAZ apud SANTi, 1997, p. 150-151)

A segunda edição, embora tenha sido mais lida e melhor recebida, não deixou de sofrer ataques fortes. Emmanuel Carballo, co-diretor da Revista Mexicana de Literatura, chamou o livro de "obra imprecisa, sinuosa, relampejante e, talvez, nociva [...] uma mescla - mal digerida - de sociologia, psicologia, história e poesia', em que 'o sofisma se justapõe à verdade, à objetividade uma subjetividade extrema e delirante"' (apud SANTI, 1997, p. 161). Paz reagiu às críticas e confirmou sua constatação de que a intelectualidade mexicana padecia de um nacionalismo ferrenho, que lhe impedia diagnosticar a crise da nacionalidade. Por isso, os temas do livro 
partiam do reconhecimento crítico da postura dos mexicanos perante o nacional: "a vergonha de ser mexicano, a consciência da festa como ritual sagrado, a cortesia como simulação, o resgate necessário do passado histórico e do legado religioso, a postulação de uma futura revelação" (SANTI, 1997, p. 136). O nacionalismo dessa inteligência, que silenciou ou reagiu com aspereza, era fundado na idéia da revolução redentora e na crença de um futuro pródigo. Aí estão as duas matrizes de que Paz trata n’O Labirinto da solidão: a celebração idealizada do futuro e o peso da tradição da revolução de 1910 na memória histórica e na cultura política mexicanas. Nelas é que baseou sua representação do México e da suposta mexicanidade. Porque o livro é, desde a primeira linha, precisamente isso: um esforço de representação - daí inclusive rechaçar, de maneira decisiva, qualquer discurso essencialista ou ontológico acerca da identidade mexicana.

Ao que tudo indica, o livro foi concebido inicialmente como um romance - escrito nos primeiros anos parisienses e jamais publicado. Segundo o próprio Paz (1993, p. 145-146), era um pastiche de D. H. Lawrence e suas apaixonadas reflexões acerca das relações entre os sexos. A opção pela ensaística, no entanto, não implicou o descarte completo das estratégias romanescas - ou, mais amplamente, ficcionais. Certas palavras ou idéias, bastante repetidas nos oito ensaios, acentuam a influência lawrenciana e a disposição para a ficção: sangue, por exemplo, ou o erotismo tomado como forma de religiosidade, mais do que prazer ou anseio de liberdade ( $P_{A Z}$, 1993, p. 148).

O ensaio literário como forma de representação - e decorrente indagação das nacionalidades - não nasceu, evidentemente, com Paz. O impacto dos recursos ficcionais, tampouco. Numa listagem arbitrária e rápida, poderíamos lembrar do importantíssimo Facundo, de Domingo Faustino Sarmiento (1845), ou de obras pouco anteriores à de Paz: Radiografia do pampa, de Ezequiel Martínez Estrada (1933), Casa grande e senzala, de Gilberto Freyre (1933) e, principalmente, Raízes do Brasil, de Sérgio Buarque de Holanda (1936). Em todos eles - e também no Labirinto - "representar" se divisa - lembra Santiago - com "desterritorializar". Santiago vai ainda mais longe e destaca outro sentido, gramaticalmente apropriado: "duplicar" (SANTiAgO, 2006, p. 20).

Foram muitos os deslocamentos - ou as duplicações - operados por Paz. Em primeiro lugar, Paz circulou entre precursores que incorporou em suas andanças pela geografia e pelas bibliotecas. Há traços do surrealismo que o marcou fundamente (sobretudo a partir de sua visita à Espanha, em 1937, e de sua estadia parisiense), juntamente com indagações trazidas da 
psicanálise: o próprio conceito de revolta que empregou (re-volta) deve bastante ao universo psicanalítico. Paz manteve distância do contexto existencialista francês em que escrevia, mas incorporou a questão existencial - no sentido estrito - da "estranheza" e do desassossego. Dialogou com o marxismo e recorreu estrategicamente a algumas de suas chaves interpretativas - principalmente no diagnóstico da dependência da condição moderna da América e nas considerações sobre identidades coletivas (em Os filhos da Malinche). Nunca, porém, assumiu seu privilégio ao coletivo, mantendo-se voltado à discussão do olhar incomparável de cada experiência individual.

A duplicação se manifesta também na capacidade de combinar, numa mesma sintonia, temas (só) aparentemente incompatíveis: o advento da modernidade e a evocação da tradição - duas questões constantes da obra de Paz. É essa disposição de trazer o passado para o presente que explica além das questões familiares - sua defesa categórica do zapatismo como possuidor da "verdade profunda" da revolução de 1910: o zapatismo teria conseguido, em sua ótica, algo que os demais grupos revolucionários não puderam ou não quiseram atingir: o reconhecimento do passado como tempo de fundação e da revolução como momento de reinvenção do México. Dessa forma, Paz traduzia um repertório de possibilidades sociais e culturais para o mexicano e permitia compatibilizar o cenário crítico da modernidade com o peso da tradição pré-colombiana, resultando numa modernidade peculiar. Assim se dá o decisivo trânsito entre história e ficção porque $O$ labirinto recupera o passado mexicano - desde o mais distante possível, anterior à conquista européia - para localizar os traços persistentes no mexicano. Quando a história chega à cena principal, Paz coordena e sincroniza, na interpretação, os vários tempos de formação do México. Consegue, assim, atravessar os séculos de colonização, a luta pela independência, os conflitos entre conservadores e liberais do XIX, a revolução de 1910 e a hegemonia ilegítima do PRI nas décadas que se seguiram à Constituição de 1917 e à derrota das revoluções camponesas.

Nesse passo, a história recuperada não é a madre de la verdad; é sua contraface: o exercício da interpretação e Paz o desenvolve através dos personagens que evoca para notar não o mexicano "essencial" - supostamente visível em algum espelho enterrado ou na identificação de uma nova e privilegiada raça ou cultura -, mas o mexicano móvel, variado, de constituição instável e desigual: o mexicano com suas inúmeras e sucessivas máscaras. É o pachuco - figura que abre o livro e: "oscila com violência e sem compasso", como "um pêndulo que perdeu a razão" (PAZ, 1984, p. 17-18). É designado 
por uma palavra de significado impreciso e de origem incerta. Deslocado na geografia e na cultura, tenta afirmar uma personalidade peculiar para responder à hostilidade que enfrenta no mundo que não é o seu - e o que supõe ser (ou ter sido) seu já não o é mais:

Perdeu toda sua herança: língua, religião, costumes, crenças. Resta-lhe apenas um corpo e uma alma à intempérie, inerme diante de todos os olhares. Seu disfarce o protege e, ao mesmo tempo, o destaca e isola: esconde-o e exibe-o. [...] Por caminhos secretos e arriscados o pachuco tenta ingressar na sociedade norte-americana. Mas ele mesmo veda este acesso. Desligado da cultura tradicional, o pachuco se afirma um momento como solidão e desafio. Nega a sociedade da qual procede e a norte-americana. O pachuco se lança para o exterior, não para se fundir com o que o cerca, mas para desafiar. Gesto suicida, pois o pachuco não afirma nada, não defende nada, exceto a sua exasperada vontade de não ser. (PAZ, 1984, p. 20)

O pachuco, esse deserdado, existe, portanto, num impasse: o da "desterritorialização" - e por isso se divide e se duplica em dois mundos e em ambos - igualmente irreais e míticos - se anula. O mesmo ocorre por trás da terrível e rancorosa designação como filhos da Chingada - mítica figura materna associada ao sofrimento e à violação, representação possível da conquista, com sua carga de brutalidade e de abertura à força. E, claro, da assumpção como filhos da Malinche que, na linha reversa e complementar da figura da Chingada, revela a entrega ao dominador: a Malinche foi a amante de Cortez e passou a designar depreciativamente os mexicanos que se abrem ao exterior. Ser filho da Chingada é identificar-se na violência e no fechamento inútil; ser filho da Malinche é abrir-se sem reservas (PAZ, 1984, p. 81). Na confluência das duas - a mãe duplicada - o contínuo contraste que a formação desigual deu ao mexicano. Ou, ainda, nos dois mexicanos: o que celebra a festa e nela se transforma e o homem reservado do quotidiano - reunidos no terceiro ensaio do livro.

Pachuco, Chingada, Malinche: são todas figuras arquetípicas que revelam a duplicidade e inscrevem a história - essa história recuperada - na esfera do mito. Porque o principal trânsito realizado por Paz em O labirinto da solidão é o que permite aproximar a história do mito e, por ele, da poesia. É também o mecanismo literário - ou a "máquina textual" (SANTiago, 2006, p. 34ss) - que permite ampliar a explicação histórica e retomar preocupações com a interpretação histórica manifestas em textos anteriores de Paz: "Para completá-la é preciso buscar uma 'metahistória': a imaginação

Júlio Pimentel. Octavio Paz e o labirinto da América Latina 
crítica que interprete mais além da história - como o mito ou o inconsciente; essa mesma 'interpretação poética da história' que o jovem poeta havia pedido uma década antes" (SANTI, 1997, p. 192).

Em sua modernidade peculiar, o México repassa os mitos que o fundaram e averigua sua adequação ao presente, além de projetá-los ao futuro - é essa, inclusive, a constatação de Paz, ao final do sexto ensaio, acerca da capacidade da revolução de 1910 de produzir e prolongar sua densa mitologia, fazendo com que seus heróis prossigam galopando pelos campos ou cruzando, nos célebres trens de campanha, o território nacional. É o repertório mítico que oferece a possibilidade de identificação - nenhuma identidade naturalizada, mas aquela constituída poeticamente em meio à história também poeticamente narrada, que remete sempre ao pessoal, à experiência irrecuperável, mas passível de ser plasmada na representação - que é também confissão de uma solidão e da perspectiva de comunhão.

\section{DENTRO DO LABIRINTO}

Diferentemente de tantos intelectuais mexicanos publicamente comprometidos com o sonho da revolução - a que já havia ocorrido ou a que se acreditava que ainda viesse a ocorrer -, Octavio Paz não se limitou, no horrível dois de outubro de 1968, aos abaixo-assinados ou aos discursos inflamados. Estava na Índia, como representante diplomático mexicano, quando soube que tropas do exército haviam aberto fogo contra cerca de dez mil pessoas, reunidas num protesto na Plaza del Tlatelolco (ou de las Tres Culturas). O saldo, nunca calculado com precisão, foi de pelo menos 300 mortos e milhares de presos e feridos. Paz escreveu um amargo poema sobre as Olimpíadas que se iniciariam poucos dias depois na mesma Cidade do México e enviou às autoridades diplomáticas sua renúncia ao posto que ocupava e à carreira. O Postdata a O labirinto da solidão, de 1970 partiu exatamente dessa tragédia para olhar com amargura a atualidade do livro de 1950. O gesto, de óbvia coragem pessoal e de estrita coerência intelectual, é normalmente esquecido, principalmente por aqueles que criticaram sua premiação em 1990 com o Nobel e o acusam por não ter endossado a retórica de defesa de ideais revolucionários-nacionalistas - os mesmos que Paz questionara já na primeira edição de $O$ labirinto da solidão e que prosseguiria criticando quando, nos últimos anos de vida e em meia dúzia de artigos (estes, sempre lembrados, embora raras vezes lidos), recusou a empolgada e superficial celebração do movimento neozapatista de Chiapas.

História Revista, Goiânia, v. 13, n. 2, p. 411-424, jul./dez. 2008 
A questão de Paz não era a revolução - pelo menos não a revolução de 1910, pelo que foi ou pelo que se construiu em torno dela na farta literatura e nos desdobramentos político-partidários que dominaram o México até o umbral do século XXI. Era a crença num futuro idealizado e estático que, embora supostamente sustentado na história, era, na prática, sua negação. Paz insistia na necessidade de perceber a integração entre história e ficção, entre mito e poesia. Era sua resposta à crise da modernidade e à dificultosa identificação do latino-americano. Queria olhar o mexicano em movimento - no tempo, no espaço, na história - e assim perceber os caminhos que o levaram, e, em boa medida, os demais latino-americanos, ao labirinto no qual insistimos em ficar presos.

Octávio Paz and the Labyrinth of Latin America

ABSTRACT: When retaking the biographical trajectory of Octávio Paz, as well as when alluding to the context of writing, of publication and of the new editions of " $O$ labirinto da solidão", it is intended to discuss the importance of the identity question in Latin America, in a general way, and in Mexico, in a particular way. Following the effort of representation of the mexican in the cited work, is sought to reevaluate the critics directed to Paz's text, considering the moment of his writing for the direct link to an identity desire, at the same time, constant and in transformation.

KeY-words: Identity, Octávio Paz, Mexico.

\section{FONTES}

PAZ, Octavio. O labirinto da solidão. Rio de Janeiro: Paz e Terra, 1984.

PAZ, Octavio. Itinerario. México: Fondo de Cultura Económica, 1993.

PAZ, Octavio. Discurso de recebimento do Prêmio Nobel de Literatura de 1990. Disponível em: <http://nobelprize.org/nobel_prizes/literature/laureates/1990/pazbio.html>. Acesso em: 15 jul. 2008, às 11 horas.

\section{REFERÊNCIAS}

Chiampi, lrlemar. O realismo maravilhoso. São Paulo: Perspectiva, 1980.

JARDIM, Eduardo. A duas vozes: Hannah Arendt e Octavio Paz. Rio de Janeiro: Civilização Brasileira, 2007.

Marques, Luiz. O modelo e a imagem. Revista Bravo, n. 47, São Paulo, ago. p. 13$15,2001$.

SANTIAGO, Silviano. As raizes e o labirinto da América Latina. Rio de Janeiro: Rocco, 2006.

Júlio Pimentel. Octavio Paz e o labirinto da América Latina 
SAnTi, Enrico Mario. El acto de las palabras. Estudios y diálogos com Octavio Paz. México: Fondo de Cultura Económica, 1997.

VAsConcelos, José. Octavio Paz y El laberinto de la soledad. In: SANTi, Enrico Mario (Org.). El laberinto de la soledad. Edición conmemorativa del 50 aniversario. México: Fondo de Cultura Económica, 2000. v. 2.

ZEA, Leopoldo. América Latina: longa viagem para si mesma. América Latina Cadernos, n. 1, São Carlos, 1982.

História Revista, Goiânia, v. 13, n. 2, p. 411-424, jul./dez. 2008 